\title{
PENGARUH MORDAN TERHADAP PENCELUPAN EKSTRAK DAUN PURING (Codiaeum Variegatum) PADA BAHAN KATUN
}

\author{
Mela Maha Revianti ${ }^{*}$, Sri Zulfia Novrita ${ }^{2 *}$ \\ Program Studi Pendidikan Kesejahteraan Keluarga, Jurusan Ilmu Kesejahteraan Keluarga \\ Fakultas Pariwisata dan Perhotelan \\ Universitas Negeri Padang \\ Jl. Prof. Dr. Hamta, Air Tawar Padang, Kel. Air Tawar Barat, Kec. Padang Utara, Kota Padang, Kode Pos 25171 \\ Sumatera Barat. Indonesia \\ Email: melamaharevianti@gmail.com
}

\begin{abstract}
Abstrak
Penelitian ini dilatar belakangi sebagai upaya untuk mengurangi dampak negative akibat penggunaan zat warna sintetis. Salah satu tanaman yang dapat dijadikan zat pewarna alam yang ramah lingkungan yaitu tanaman puring. Hasil pewarnaan dengan mordan asam kandis menghasilkan warna Warm Brown, Value cukup terang dan kerataan pada kategori rata, dengan mordan garam menghasilkan warna Pale Cyan, Value cukup gelap dan kerataan pada kategori cukup rata, dengan mordan jeruk nipis menghasilkan warna Warm Brown, Value cukup terang dan kerataan pada kategori cukup rata, dengan mordan kapursirihmenghasilkan $100 \%$ warna Pale Yellow, Value sangat terang dan kerataan pada kategori kurang rata dan hasil dengan mordan tawas menghasilkan warna Clam Shell Pink dengan Value cukup terang dan kerataan pada kategori sangat rata, Hasil uji Friedman K-Related Sample diperoleh untuk gelap terang warna (Value) adalah $0,000<0,05$, maka $\mathrm{H}_{\mathrm{o}}$ ditolak, artinya terdapat pengaruh gelap terang warna yang signifikan dan hasil untuk kerataanwarna, data yang diperoleh adalah $0,000<0,05$ maka $\mathrm{H}_{\mathrm{o}}$ ditolak, artinya terdapat pengaruh yang signifikan pada pencelupan ekstrak daun puring (Codiaeum Variegatum) menggunakan mordan asam kandis (Garcinia xanthochymus), garam (Nacl), jeruk nipis (citrus Aurantifolia), kapur sirih (calcium hidroksida) dan tawas pada bahan katun.
\end{abstract}

Kata Kunci: pengaruh, mordan, daun puring.

\begin{abstract}
This research is motivated as an effort to reduce the negative effects caused by the use of synthetic dyes. One of the plants that can be used as natural coloring agents which is environmentally friendly is croton plant. The results of staining with mordan candis acid produce Warm Brown color, Value is quite bright and flatness in the flat category, with mordan salt producing Pale Cyan color, Value is quite dark and flatness in the category is quite flat, with mordan lime produces Warm Brown color, Value is quite bright and evenness in the category is quite flat, with mordan whiting producing Pale Yellow color, Value is very bright and evenness in the uneven category and results with mordan alum produce color Clam Shell Pink with a light enough value and flatness in the very flat category, the Friedman K-Related Sample test results obtained for light dark colors (Value) is $0,000<0.05$, then $H_{o}$ is rejected, meaning that there is a significant effect of dark light colors and results for color flatness, the data obtained is $0,000<0.05$ then $H_{o}$ is rejected, meaning that there is a significant influence on the dyeing of croton leaf extract (CodiaeumVariegatum) $m$ use mordan candis acid (Garcinia xanthochymus), salt (Nacl), lime (citrus Acurantifolia), betel lime (calcium hydroxide) and alum in cotton.
\end{abstract}

Keywords: influence, mordant, croton..

\section{PENDAHULUAN}

Seiring dengan perkembangan zaman diperkirakan citra zat warna alami akan kembali bangkit. Zat warna alami telah banyak digunakan, namun terlupakan karena adanya zat warna sintetis yang lebih praktis dalam penggunaannya. Menurut Sunaryati dkk (2000:103) Menyimpulkan, "Pemakaian zat warna sintetis bahaya bagi kesehatan, karena zat warna sintetis bersifat karsinogen. Berbagai negara seperti
Jerman, Perancis, Belgia, Amerika dan Jepang melarang impor tekstil dan produk tekstil yang menggunakan zat warna sintetis jenis azo ataupun yang mengandung Bahan Beracun dan Berbahaya (B3) yang lain".

Oleh karena itu , pemanfaatan zat warna alami sebagai langkah yang tepat untuk mengatasi dampak negatif dari penggunaan zat pewarna sintetis. Salah satu 
tumbuhan dari alam yang menghasilkan zat pewarna alami adalah tanaman daun puring

Tanaman puring termasuk tanaman liar yang banyak dijumpai tumbuh di semak-semak, memiliki daun kecil-kecil panjang, untuk tanaman puring daun kecil ini menyukai suhu sekitar $30^{\circ} \mathrm{C}$. Dibawah suhu $15^{\circ}$ pertumbuhan daun terhambat dan rentan terserang akar busuk. Puring mempunyai rasa pahit, bersifat dingin dan beracun, akar dan kulit batangnya berasa pedas. Menurut Ambarwati (2007:37) "Puring berasal dari Indonesia, tepatnya di Maluku, Nama latin untuk puring adalah Codiaeum Variegatum pictum ada yang menyebut croton, tanaman ini termasuk tumbuhan semaksemak serta dapat mencapai tinggi 1-5 meter". Menurut Kadir (2008:8) pengelompokan ilmiah tanaman puring adalah "(1) kingdom: plantae, (2) Division: Magnoliophyta, (3) Class: Magnoiopsida, (4) Order: Malpighiales, (5) Family: Euphorbiaceae, (6) Subfamily: Crotonoideae, (7) Tribe: Codiaea, (8) Genus: Codiaeum variegatum”.

Tanaman puring (Codiaeum Variegatum) termasuk tanaman yang mudah dalam penanaman dan pembudidayaan karena tanaman puring ini memiliki zat aktif yang menimbulkan warna yakni antosianin. Menurut K Monika (2015:2) menyatakan, "Bentuk dan warna yang beragam dari tanaman puring puring menyulitkan para ahli botani dalam melakukan klsifikasi, warna dan corak yang beragam membuat tanaman puring terlihat berbeda meskipun memiliki bentuk yang mirip, akan tetapi pengel

ompokan warna bisa dibuat menjadi lebih sederhana dengan mengelompokkannya kedalam tiga warna pokok yang dipengaruhi tiga pigmen utama pada tanaman yaitu warna hijau, warna merah dan warna kuning. Warna hijau dipilih karena pada daun terdapat klorofil yang memberikan warna hijau, selain klorofil tanaman puring juga mengandung antosianin dalam bentuk flavonoid yang memberikan warna merah dan karotenoid yang memberikan warna kuning".

Prosespencelupan dilakukan dengan cara melarutkan zat warna alami yang telah menjadi ekstrak dari rebusan daun puring sehingga menghasilkan warna pada bahan, proses pencelupan warna alam memerlukan zat yang disebut mordan, Mordan berfungsi untuk meningkatkan afinitas zat warna terhadap serat sehingga warna dari pencelupan tidak mudah luntur. Menurut Hasanudin (2001: 15) "pemberian mordan bertujuan untuk memperbesar daya serap kain terhadap zat warna”. Selain itu mordan sebagai zat penguat dan pembangkit warna dapat mempengaruhi warna akhir dalam proses pewarnaan.
Mordan yang digunakan dalam pencelupan sangat berpengaruh terhadap warna yang dihasilkan. Berdasarkan pembahasan diatas tujuan penelitian ini adalah 1) mendeskripsikan nama warna, 2) mendeskripsikan gelap terang warna, 3) mendeskripsikan kerataan warna 4) pengaruh gelap terang dan 5) pengaruh kerataan warna yang dihasilkan oleh pencelupan ekstrak daun puring pada bahan katun.

\section{KAJIAN TEORI}

Pencelupan merupakan proses pemberian warna pada bahan tekstil secara merata dengan menggunakan media air. Menurut Sunarto (2008:151) "Pencelupan pada umumnya terdiri dari melarutkan atau mendispersikan zat warna dalam air atau medium lain, kemudian memasukkan bahan tekstil kedalam larutan tersebut sehingga terjadi penyerapan zat warna kedalam serat". Menurut menurut Surakhmad (1982:7) "Pengaruh adalah kekuatan yang muncul dari suatu benda atau orang dan juga gejala yang dapat memberikan perubahan terhadap apa-apa yang ada disekelilingnya". Tanaman puring termasuk tanaman yang mudahdalam penanaman dan pembudidayaan karena tanaman puring ini termasuk tanaman liar yang banyak dijumpai tumbuh di semak-semak, memiliki daun kecil-kecil panjang.

Untuk tanaman puring daun kecil ini menyukai suhu sekitar $30^{\circ} \mathrm{C}$. dibawah suhu $15^{\circ}$ pertumbuhan daun terhambat dan rentan terserang akar busuk. Puring mempunyai rasa pahit, bersifat dingin dan beracun, akar dan kulit batangnya berasa pedas. Menurut Ambarwati (2007:37) "Puring berasal dari Indonesia, tepatnya di Maluku, Nama latin untuk puring adalah Codiaeum Variegatum pictuma ada yang menyebut croton, tanaman ini termasuk tumbuhan semak-semak serta dapat mencapai tinggi 1-5 meter".

Dalam roses pencelupan dibutuhkan zat mordan. Mordan adalah zat khusus yang dapat meningkatkan lekatnya warna dan bentuk pada kain. Menurut Susanto (1980:71) "Mordan merupakan suatu zat yang dipergunakan dalam proses pencelupan agar warna yang terserap ke dalam kain lebih kuat dan dapat dipergunakan sebelum atau sesudah proses pencelupan kain".

Menurut Noor (2007:2) "Bahan tekstil yang diwarnai dengan zat warna alam adalah bahan-bahan yang berasal dari serat alam contohnya sutera, wol dan katun (kapas)". Berdasarkan karkteristik dan sifat-sifat katun maka penulis memilih bahan katun. 


\section{METODE PENELITIAN}

Jenis penelitian yang dilakukan adalah penelitian eksperimen. Menurut Sukardi (2003:179) "Penelitian eksperimen pada prinsipnya dapat didefinisikan sebagai metode sistematis guna membangun hubungan yang mengandung fenomena sebab akibat (Causaleffect relatioship). Dalam penelitian penulis melakukan eksperimen terhadap bahan Katun yang dicelup dengan zat warna alami estrak daun puring (Codiaeum variegatum) dengan menggunakan mordan Asam Kandis (Garcinia xanthochymus) Garam (Nacl), Jeruk nipis (citrusAurantifolia), kapur sirih (calciumhidroksida) dan tawas.

Dalam penelitian ini, zat warna yang digunakan adalah estrak daun puring (Codiaeum variegatum) dengan menggunakan mordan Asam Kandis (Garcinia xanthochymus) Garam (Nacl), Jeruk nipis (citrus Aurantifolia), kapur sirih (calcium hidroksida) dan tawas.dengan perlakuan yang sama baik dari bahan, alat dan waktu. Perbedaannya pada mordan.

Data yang terkumpul diolah diberi nilai dan disusun dalam bentuk tabel, kemudian dianalisa dengan menggunakan persentase untuk menentukan warna yang dihasilkan oleh ekstrak daun puring (Codiaeum variegatum) dengan mordan Asam Kandis (Garcinia xanthochymus) Garam (Nacl), Jeruk nipis (citrus Aurantifolia), kapur sirih (calcium hidroksida) dan tawas.Jenis Jenis penelitian ini adalah penelitian eksperimen, Teknik analisis data menggunakan uji Friedman K-Related Sample Untuk mendeskripsikan hasil pewarnaan terhadap nama warna, gelap terang, kerataan warna, pengaruh gelap terang dan pengaruh kerataan warna yang dihasilkan pada pencelupan estrak daun puring dengan menggunakan mordan Asam Kandis, Garam, Jeruk nipis, kapur sirih dan tawas, pengolahan data menggunakan program SPSS (Statistical Product and Service Solutions) versi 16.0.

\section{HASIL DAN PEMBAHASAN}

\section{Hasil}

Data hasil penelitian meliputi variable analisis umum hasil penelitian, variable $\mathrm{x}$ adalah pengaruh mordan terhadap hasil pencelupan ekstrak daun puring pada bahan katun. Sedangkan variable Y Variabel Y pada penelitian ini adalah pengaruh mordan terhadap hasil pencelupan berupa nama warna, gelap terang warna dan kerataan warna.
Tabel 1. Nama Warna yang Dihasilkan.

\begin{tabular}{|c|c|c|c|c|c|c|}
\hline No & Pencelupan & Wama & $\begin{array}{c}\text { Nama } \\
\text { Wama }\end{array}$ & F & $\%$ F & RGB \\
\hline 1. & Asam & & $\begin{array}{c}\text { Warm } \\
\text { Krown }\end{array}$ & 14 & $\begin{array}{r}77,7 \\
7 \%\end{array}$ & $\begin{array}{c}\text { R 221 } \\
\text { G 137 } \\
\text { B 151 }\end{array}$ \\
\hline 2. & Garam & & $\begin{array}{c}\text { Pale } \\
\text { Cyan }\end{array}$ & 14 & $\begin{array}{c}77,7 \\
7 \%\end{array}$ & $\begin{array}{c}\text { R 166 } \\
\text { G 170 } \\
\text { B 178 }\end{array}$ \\
\hline 3. & Jeruk Nipis & & $\begin{array}{c}\text { Warm } \\
\text { Brown }\end{array}$ & 15 & $\begin{array}{c}83,3 \\
3 \%\end{array}$ & $\begin{array}{c}\text { R 231 } \\
\text { G 194 } \\
\text { B 185 }\end{array}$ \\
\hline 4. & Kapur Sirih & & $\begin{array}{c}\text { Pale } \\
\text { Yellow }\end{array}$ & 18 & $\begin{array}{c}100 \\
\%\end{array}$ & $\begin{array}{c}\text { R 250 } \\
\text { G 251 } \\
\text { B 185 }\end{array}$ \\
\hline 5 & Tawas & & $\begin{array}{c}\text { Clam } \\
\text { shell } \\
\text { pink }\end{array}$ & 15 & $\begin{array}{c}83,3 \\
3 \%\end{array}$ & $\begin{array}{c}\text { R 216 } \\
\text { G 202 } \\
\text { B 199 }\end{array}$ \\
\hline
\end{tabular}

Tabel 2. Gelap Terang Warna yang Dihasilkan.

\begin{tabular}{|c|c|c|c|}
\hline Mordan & $\begin{array}{c}\text { Gelap } \\
\text { terang } \\
\text { (Value) }\end{array}$ & $\mathbf{F}$ & $\%$ Frekuensi \\
\hline Asam kandis & $\begin{array}{l}\text { Cukap } \\
\text { terang }\end{array}$ & 12 & $66,66 \%$ \\
\hline Garam & Coukup gelap & 7 & $38,88 \%$ \\
\hline Jenuk nipis & $\begin{array}{l}\text { Cukup } \\
\text { terang }\end{array}$ & 11 & $61,11 \%$ \\
\hline Kapur sirih & $\begin{array}{l}\text { Sangat } \\
\text { terang }\end{array}$ & 12 & $66,66 \%$ \\
\hline Tawas & $\begin{array}{l}\text { Cukap } \\
\text { terang }\end{array}$ & 10 & $55,55 \%$ \\
\hline
\end{tabular}

Berdasarkan tabel di atas gelap terang warna yang dihasilkan terlihat cukup gelap pada mordan garam dan sangat terang pada mordan kapur sirih.

Tabel 3. Keterawatan Warna yang Dihasilkan.

\begin{tabular}{|c|l|c|c|}
\hline No & $\begin{array}{c}\text { Kerataan } \\
\text { Warna }\end{array}$ & Frekuensi & $\begin{array}{c}\% \\
\text { Frekuensi }\end{array}$ \\
\hline $\begin{array}{c}\text { Asama } \\
\text { kandis }\end{array}$ & Rata & 14 & $77,77 \%$ \\
\hline Garama & Rata & 14 & $77,77 \%$ \\
\hline $\begin{array}{c}\text { Iernk } \\
\text { nipis }\end{array}$ & Cukap rata & 11 & $61,11 \%$ \\
\hline $\begin{array}{c}\text { Kapur } \\
\text { siinh }\end{array}$ & $\begin{array}{l}\text { Kurang } \\
\text { rata }\end{array}$ & 17 & $94,44 \%$ \\
\hline Tawas & Sangat rata & 9 & $50 \%$ \\
\hline
\end{tabular}

Pada tabel di atas dapat dilihat kerataan warna yang dihasilkan menurut data dari panelis adalah kurang rata pada mordan kapur sirih dan sangat rata pada mordan tawas.

Tabel 4. Hasil Uji Friedman K-related Sampel Pengaruh Gelap Terang Warna (Value) yang Dihasilkan pada Pencelupan Bahan Katun.

\begin{tabular}{|c|c|}
\hline N & 18 \\
Chi-Square & 27.829 \\
Df & 4 \\
Asymp. Sig. & .000 \\
\hline
\end{tabular}


Pada uji k-related sample tabel diatas diperoleh nilai 0,00 yang lebih kecil dari taraf signifikansi 00,05, itu artinya terdapat pengaruh gelap terang warna akibat mordan asam kandis, garam, jeruk nipis, kapur sirih dan tawas.

Tabel 5. Hasil Uji Friedman K-related Sampel Gelap Kerataan Warna yang Dihasilkan pada Pencelupan Bahan Katun.

\begin{tabular}{|c|c|}
\hline $\mathrm{N}$ & 18 \\
Chi-Square & 13.235 \\
Df & 1 \\
Asymp. Sig. & .000 \\
\hline
\end{tabular}

Pada tabel pengaruh kerataan warna di atas diperoleh nilai 0,00 yang lebih kecil dari taraf signifikansi 00,05, itu artinya terdapat pengaruh kerataan warna akibat mordan asam kandis, garam, jeruk nipis kapur sirih, dan tawas.

\section{Pembahasan}

Berdasarkan hasil penelitian dijelaskan nama warna yang dihasilkan oleh pencelupan ekstrak daun puring dengan mordan asam kandis $77,77 \%$ panelis memilih Warm Brown, dengan mordan Garam 77,77\% panelis memilih Pale Cyan, dengan mordan Jeruk nipis 83,33\% panelis memilih Warm Brown, dengan mordan kapur sirih $100 \%$ panelis memilih pale yellow dan dengan mordan Tawas 83,33\% panelis memilih Clam Shell Pink.

Menurut K Monika tanaman puring mengandung antosianin dalam bentuk flavonoid yang merupakan pigmen penimbul warna yang dapat dijadikan pewarna alam. Dengan pemberian mordan asam kandis, garam, jeruk nipis, kapur sirih dan tawas pencelupan ekstrak daun puring menghasilkan warna yang berbeda sesuai kandungan zat yang terkandung di dalam mordan tersebut.

Gelap terang warna pada pencelupan bahan katun menggunakan ekstrak daun puringdengan mordan Asam Kandis $66,66 \%$ panelismenyatakan CukupTerang,Mordan Garam38,88\% panelis menyatakan Cukup Gelap, Mordan Jeruk nipis $61,11 \%$ panelis menyatakan Cukup Terang,Mordan kapur sirih 66,66\% panelis menyatakan Sangat Terang dan Mordan Tawas 55,55\% panelis menyatakan Cukup Terang.

Berdasarkan analisis terhadap gelap terang warna yang dihasilkan pencelupan bahan katun menggunakan ekstrak daun puring denga nmordan asam kandis kategori cukup terang, hal ini sejalan
Gorga Jurnal Seni Rupa

Volume 08 Nomor 02 Juli-Desember 2019 p-ISSN: 2301-5942 | e-ISSN: 2580-2380

dengan jurnal Almagita, Rachmy Bunga, Sri Zulfia Novrita, and Weni Nelmira, (2018) yang berjudul "Pengaruh penggunaan mordan asam jawa (Tamarindus indicalinn) dan Asamkandis (Garcinia Parvifolia Miq) terhadap hasil pencelupan Bahan Sutera", menyatakan bahwa kategori Value yang dihasilkan oleh mordan asam kandis cukup terang.

Kerataan warna yang dihasilkan oleh pencelupan ekstrak daun puring pada bahan katun dengan mordan asam kandis, 77,77\% panelis menyatakan rata, dengan mordan Garam 77,77\% panelis menyatakan cukup rata, dengan mordan Jeruk nipis $61,11 \%$ panelis menyatakan cukup rata, dengan mordan kapur sirih $94,44 \%$ panelis menyatakan Kurang Rata dan dengan mordan tawas $50 \%$ panelis menyatakan Sangat Rata.

Berdasarkan analisis terhadap kerataan warna yang dihasilkan mordan Kapursirih kategori kerataan warna kurang rata, hal ini berbandin gterbalik dengan jurnal dari Fatihaturahmi, SZ Novrita. (2019) dengan judul Pengaruh Perbedaan Mordan Tawas dan Kapur Sirih terhadap hasil pencelupan ekstrak daun Sawo Menggunakan Bahan Sutera menyatakan bahwa pencelupan ekstrak daun sawo menggunakan mordan kapur sirih dengan kategori rata.

Pada mordan tawas kategori kerataan warna sangat rata, hal ini sejalan dengan jurnal dari Ramelawati, R., Adriani, A., \& Novrita, S. Z. (2018) yang berjudul "Pengaruh mordan tawas dan jeruk nipis (Citrus Aurantifolia) terhadap hasil pencelupan Ekstrak Bawang Merah (Allium Ascalonium L) pada bahan Sutera", menyatakan bahwa pada mordan tawas kerataan warna pada kategori sangat rata.

Berdasarkan analisis yang diperoleh dari uji Friedman K-Related Sample untuk gelap terang warna (Value) data yang diperoleh dari pencelupan ekstrak daun puring (Codiaeum Variegatum) dengan menggunakan mordan Asam Kandis (Garcinia xanthochymus) Garam (Nacl), Jeruk nipis (citrusAurantifolia), kapur sirih (calcium hidroksida) dan tawas, padabahan katun adalah 0,000 yang lebih kecil dari taraf signifikansi sebesar 0,05 atau $0,000<0,05$ artinya $\mathrm{H}_{\mathrm{o}}$ ditolak. Dari penjelasan tersebut dapat diambil kesimpulan bahwa terdapat pengaruh yang signifikan terhadap gelap terang warna (Value) pada pencelupan ekstrak daun puring ( Codiaeum Variegatum) dengan menggunakan mordan Asam Kandis (Garcinia xanthochymus) Garam (Nacl), Jeruk nipis (citrus Aurantifolia), kapur sirih (calcium hidroksida) dan tawas. Hal ini sejalan dengan jurnal Almagita, Rachmy Bunga, Sri Zulfia Novrita, and Weni Nelmira, (2018) yang berjudul "Pengaruh 
penggunaan mordan asam jawa (Tamarindus indica linn) dan Asam kandis (Garcinia Parvifolia Miq) terhadap hasil pencelupan Bahan Sutera", menyatakan bahwa terdapat pengaruh yang signifikan terhadap gelap terang warna pada hasil pencelupan bahan katun menggunakan ekstrak buah Senduduk (Melatosma Malabathricum).

Berdasarkan analisis yang diperoleh dari uji Friedman $K$-Related Sample untuk kerataan warna data yang diperoleh dari pencelupan ekstrak daun puring (Codiaeum Variegatum) dengan menggunakan mordan Asam Kandis (Garcinia xanthochymus) Garam (Nacl), Jeruk nipis (citrus Aurantifolia), kapur sirih (calcium hidroksida) dan tawas, pada bahan katun adalah 0,000 yang lebih kecil dari taraf signifikansi sebesar 0,05 atau $0,000<0,05$ artinya $\mathrm{H}_{\mathrm{o}}$ ditolak. Dari penjelasan tersebut dapat diambil kesimpulan bahwa terdapat perbedaan yang signifikan terhadap kerataan warna pada pencelupan ekstrak daun puring ( Codiaeum Variegatum) dengan menggunakan mordan Asam Kandis (Garcinia xanthochymus) Garam (Nacl), Jeruk nipis (citrusAurantifolia), kapur sirih (calcium hidroksida) dan tawas.

Hal ini berbanding terbalik dengan dengan jurnal dari Fatihaturahmi, SZ Novrita. (2019) dengan judul Pengaruh Perbedaan Mordan Tawas dan Kapur Sirih terhadap hasil pencelupan ekstrak daun Sawo Menggunakan Bahan Sutera menyatakan bahwa, tidak terdapat pengaruh yang signifikan terhadap kerataan warna yang dihasilkan pencelupan ekstrak daun sawo menggunakan bahan sutera mordan Tawas dan kapur sirih.

\section{KESIMPULA DAN SARAN}

\section{Kesimpulan}

\section{1). Nama Warna (Hue)}

Nama warna pada pencelupan bahan katun menggunakan ekstrak daun puring dengan mordan Asam Kandis menghasilkan warna Warm Brown (77,77\%), Mordan Garam menghasilkan warna Pale Cyan (77,77\%), dengan mordan Jeruk nipis menghasilkan warna Warm Brown kode $(83,33 \%)$, dengan mordan kapur sirih menghasilkan warna Pale Yellow (100\%) dan dengan mordan Tawas menghasilkan warna Clam Shell Pink (83,33\%).

\section{2). Gelap Terang Warna (Value)}

Gelap terang warna pada pencelupan bahan katun menggunakan ekstrak daun puring dengan mordan Asam Kandis CukupTerang (66,66\%),dengan mordan garam Cukup Gelap (38,88\%), dengan mordan Jeruk nipis Cukup Terang $(61,11 \%)$, dengan mordan kapur sirih Sangat Terang $(66,66 \%)$ dan dengan mordan Tawas Cukup Terang $(55,55 \%)$.

\section{3). Kerataan Warna}

Berdasarkan hasil pencelupan bahan katun menggunakan ekstrak daun puring dengan mordan asam kandis Rata $(77,77 \%)$, dengan mordan Garam cukuprata $(77,77 \%)$, dengan mordan Jeruk nipis cukuprata $(61,11 \%)$, dengan mordan kapur sirih Kurang Rata $(94,44 \%)$ dan dengan mordan tawas Sangat Rata (50\%).

\section{4). PengaruhGelap Terang Warna yang Dihasilkan}

Berdasarkan hasil uji K-Related samplebahwa terdapat pengaruh yang signifikan akibat pengaruh mordan Asam Kandis, Garam, Jeruk nipis, kapur sirih dan tawas terhadap Gelap Terang warna yang dihasilkan pada pencelupan bahan katun menggunakan ekstrak daun puring.

\section{5). Pengaruh Kerataan Warna yang Dihasilkan}

Berdasarkan hasil uji K-Related Sampleterdapat pengaruh yang signifikan akibat mordan Asam Kandis, Garam, Jeruk nipis, kapur sirih dan tawas terhadap kerataan warna yang dihasilkan pada pencelupan bahan katun menggunakan ekstrak daun puring.

\section{Saran}

Bagipenulis agar dapat memanfaatkan ilmu yang telah penulis dapatkan dari eksperimen ini, bagi Jurusan Ilmu Kesejahteraan Keluarga tentang penelitianini diharapkan dapat menambah referensi untuk pencelupan kedepannya, agar pencelupan zat warna alam lebih baik lagi. Hasil penelitian ini juga dapat menjadi bahan pertimbangan dalam pencelupan. Untuk pewarnaan Perlu dilakukan penelitian lebih lanjut tentang mordan yang lain sehingga dapat diperoleh hasil pewarnaan yang bervariasi tentang pemanfaatan zat alam yang lain dan juga mengatasi dampak negative dari penggunaan zat pewarna sintetis.

\section{DAFTAR RUJUKAN}

Ambarwati, Siti. (2007). Budidaya Tanaman Hias. Jakarta: Azka Press.F

Almagita, Rachmy Bunga, Sri Zulfia Novrita, and Weni Nelmira. ( ). Pengaruh Penggunaan Mordan Asam Jawa ( $T$ amarindus Indica Linn) dan Asam Kandis (Garcinia Parvifolia Miq) terhadap Hasil Pencelupan Bahan Sutera dengan Meng gunakan Ekstrak Daun Andong (Cordyline F 


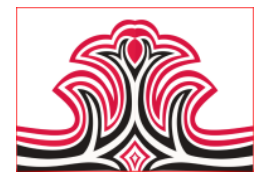

ruticosa LA Cheval)."

) ,

Fatihaturahmi, SZ Novrita. (2019). Pengaruh Perbedaan Mordan Tawas dan Kapur Sirih Terhadap Hasil Pencelupan Ekstrak Daun Sawo Menggunakan Bahan Sutera. Gorga Jurnal Seni Rupa, 08(01), 237-242.

Hasanudin. (2001). Penelitian Penerapan Zat Warna Alam dan Kombinasinya pada Produk Batik dan Tekstil Kerajinan. Yogyakarta: Balai Besar Penelitian dan Pengembangan Industri Kerajinan Batik.

Kadir. (2008). Tanaman Hias Bernuansa Varigata. Yogyakarta: Lily Publister.

K, Monika Andreastuti, dkk. (2015). Keragaman Molekul Puring (Codiaeum Variegatum $(L)$ Rump. Ex. A. Juss) dengan Penanda Rapd. Yogyakarta: Fakultas Pertanian Universitas Gadjah Mada.

R Ramelawati, A Adriani, and SZ Novrita. (2018) . Pengaruh Mordan Tawas dan Jeruk Nipis (Citrus Aurantifolia) terhadap Hasil Pencelupan Ekstrak Bawang Merah (Allium Ascalonium L) pada Bahan Sutera. E-Journal Home Economic and Tourism, __ ( ),

Sunaryati, S., and S. Hartini, dan Ernaningsih. (2000). Pengaruh Tatacara Pencelupan Zat Warna Alam Daun Sirih pada Hasil Pencelupan Kain Sutera. Prosiding Pertemuan dan Presentasi Ilmiah Penelitian Dasar Ilmu Pengetahuan dan Teknologi Nuklir P3TM. Yogyakarta: Badan Tenaga Atom Nasional.

Sunarto. (2008). Teknologi Pencelupan dan Pencapan SMK jilid II. Jakarta: Direktorat Pembinaan Sekolah Menengah Kejuruan.

Surakhmad. (1982). Pengantar penelitian ilmiah, dasar, metode dan teknik. Bandung: Tarsito.

Susanto. (1980). Seni Kerajinan Batik Indonesia. Yogyakarta: Balai Penelitian. 